\section{Coping Behavior in a Situation of Voluntary Migration}

\author{
N. V. Usova \\ Institute of Social Education (branch) Russian State Social University \\ 4, Fabrichnaya str., Saratov, 410015, Russia \\ E-mail: usova_natalia@mail.ru
}

The study examines the adaptation process of foreign students residing in the territory of the Russian Federation. Determine the level and the dominating type of socio-cultural adaptation, reveals the degree of social frustration and coping strategies of foreign citizens living in Russia. Special attention is devoted to the study of coping strategies of foreign students living in voluntary migration, revealed the adaptation potential of the personality, as well as the most effective and ineffective ways of coping in situations of high emotional tension. It is revealed that migrants are more likely to shape their behavior under the influence of the expectations of the group depending on the degree of their interest in achieving its goals and expected remuneration, the research results allowed to state migrants with a high level of adaptive capacity. It is concluded that the social-psychological work with migrants is necessary in order to create comfortable living conditions, but the development of their independence and maximize their available personal resources. It is recommended that when developing an effective programme of psychosocial support for migrants to take into account the peculiarities of their coping strategies.

Key words: migration, adaptive capacity, socio-cultural adaptation, coping strategies, stress.

\section{References}

1. Lazarus R. S., Folkman S. The concept of coping. Stress and coping: An anthology. Ed. by A. Monat, R. S. Lazarus. New York, 1991, pp. 189-206.
2. Usova N. V. Struktura i sotsialno-psikhologicheskie faktory subektivnogo blagopoluchiya lichnosti v usloviyakh migratsii: avtoref. dis. ... kand. psikhol. nauk (Structure and socio-psychological factors of subjective well-being of the individual in terms of migration: thesis ... Ph/D in psychology). Saratov, 2012. 24 p.

3. Smirnov A. S. Izuchenie zhiznennykh planov potentsialnykh emigrantov (A study of the life plans of potential emigrants). Chelovek v psikhologii: orientiry issledovaniya v novom stoletii: materialy konf. (20 aprelya 2001 g., Karaganda) (Person in psychology: goals of research in the new century: Proceedings of the conference $\{20$ April 2001, Karaganda\}). Karaganda, 2001, pp. 179-184.

4. Lebedeva N. M. Sotsialnaya psikhologiya etnicheskikh migratsiy (Social psychology of ethnic migrations). Moscow, 1993. 195 p.

5. Kryukova T. L., Kuftyak E. V. Oprosnik sposobov sovladaniya (adaptatsiya metodiki WCQ) (Questionnaire ways of coping \{adaptation test WCQ\}). Zhurnal prakticheskogo psikhologa (Journal of the practical psychologist), 2007, no. 3, pp. 93-112.

6. Kozlov V. V., Fetiskin N. P., Manuylov G. M., Sotsialnopsikhologicheskaya diagnostika razvitiya lichnosti $i$ malykh grupp: ucheb. posobie (Socio-psychological diagnostics of the development of personality and small groups). Moscow, 2002. $490 \mathrm{p}$.

7. Adaptatsiya lichnosti $k$ novoy sotsiokulturnoy srede (test L. V. Yankovskogo) (The adaptation to a new sociocultural environment \{test L. V. Yankovsky\}). St.-Petersburg, 2004, pp. 206-211.

8. Gritcenko V. V. Sotsialno-psikhologicheskaya adaptatsiya pereselentsev $v$ Rossii (Socio-psychological adaptacion of migrants in Russia). Moscow, 2002. 252 p. \section{л. С. ВыгОтСКИЙ \\ Шатова Наталья Дмитриевна - \\ кандидат педагогических наук, доцент, научный сотрудник отдела организации и планирования научно-исследовательских работ, Омский государственный педагогический университет E-mail: Shatova.nat@yandex.ru}

ПРОЛЕГОМЕНЫ К ПОИСКУ РЕФЛЕКТОРНЫХ ОСНОВ РЕФЛЕКСИИ:

Попытки внедрения рефлексивного подхода в отечественное образование чаще всего оказывались безуспешными, что, по мнению автора, обусловлено невниманием к материалистической позиции психологов, согласно которой эффективно формировать рефлексивные способности обучающихся возможно, опираясь на хорошо изученные законы управления формированием условных рефлексов человека. В этой связи автор ищет связь между рефлексией и рефлексом для того, чтобы в последующем использовать её в качестве фундаментальной основы концепции рефлексивного обучения. Связь между рефлексией и рефлексом устанавливается опосредованно - через «мышле-

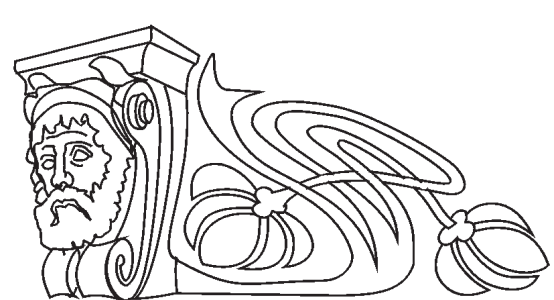

ние» - и в поиске аргументов в пользу рефлекторной природы мышления мы обращаемся к работам Л. С. Выготского.

Ключевые слова: Л. С. Выготский, мышление, рефлекс, рефлексия.

\section{DOI: $10.18500 / 1819-7671-2016-16-1-99-103$}

Современная система отечественного образования нуждается в решении проблем, порождённых её «обновлением», - разрушена «традиционная школа» и на смену ей импор- 
тируются различные нововведения. Часто внедрение новшеств осуществляется не только на неподготовленную почву, но и необоснованно, В результате испробованные за последние годы различные подходы к методам, технологиям и содержанию образования, периодически сменяя друг друга, в конце концов потеряли свои чёткие очертания и показали свою неэффективность. Особую надежду в последнее время возлагают на «самоорганизацию» образовательного процесса. Однако и «самоорганизация» не решает всех проблем [1].

Но, несмотря на сложившуюся в педагогической науке и образовательном пространстве ситуацию, характеризующуюся плюрализмом мнений, ретроспективный взгляд помогает выделить две фундаментальные линии, ведущие к философским истокам, в которых отражена мировоззренческая проблема активности и реактивности человека. С нашей точки зрения, оппозиция между этими философско-мировоззренческими установками нашла компромиссное решение в отечественной психологии - материалистическом учении о рефлексах и теории деятельности. Именно теория деятельности объединяет в себе рефлексивную активность мысли и рефлекс как её фундаментальную физиологическую основу. Но ещё до работ А. Н. Леонтьева в отечественной психологической науке были заложены материалистические основы понимания рефлексии. Традиционно исследованием проблемы рефлексии занимались и занимаются учёные различных научных областей, в частности, философии, психологии, кибернетики, педагогики, что свидетельствует о междисциплинарном её характере. В зависимости от научной области исследования выявляется определённая грань рефлексии и акцент делается на том или ином её аспекте. Чаще всего к изучению рефлексии подходят в русле идеалистической традиции (без привязки к «носителю» механизма рефлексии), при этом материалистическая традиция в изучении рефлексии представлена не столь широко, хотя, с нашей точки зрения, для целей образования именно этот подход является наиболее продуктивным. Будучи сторонниками материалистической онтологии и гносеологии, мы полагаем, что эффективное рефлексивное обучение возможно лишь при установлении взаимосвязи рефлексии и высших рефлексов головного мозга. В этой связи целью нашего исследования является поиск и раскрытие материалистических основ рефлексии, что в дальнейшем может быть использовано в качестве фундаментального ядра концепции рефлексивного обучения.
Изучение работ отечественных психологов и физиологов позволяет очертить круг, в котором возможен поиск материалистических основ рефлексии. Это те учёные, которые связывали психику с физиологией высшей нервной деятельности: И. М. Сеченов, В. М. Бехтерев, И. П. Павлов, П. К. Анохин, Н. А. Бернштейн, Л. С. Выготский, С. Л. Рубинштейн, А. Н. Леонтьев, П. Я. Гальперин, К. К. Платонов, К. В. Судаков, П. В. Симонов, Н. П. Бехтерева и др.

Ранее в рамках исследования генезиса понятия «рефлекс» [2-4] мы изучили результаты исследований психической деятельности, полученные классиками рефлекторной теории И. М. Сеченовым и И. П. Павловым, на которые мы и далее будем опираться, выделив в качестве исходного тезис, что психическая деятельность есть условно-рефлекторная деятельность.

В отечественной психологии традиция, идущая от И. М. Сеченова и И. П. Павлова, была продолжена в работах вышеназванных учёных, среди которых первостепенное значение имеют труды Л. С. Выготского. С его точки зрения, психическая деятельность как условно-рефлекторная «представляет собой, в сущности, те же наследственные реакции, но в расчленённом, комбинированном виде, и возникают они в совершенно новых связях с элементами среды» $[5$, c. 73$]$.

В работах отечественных физиологов и психологов довольно распространённым является положение о связи психической деятельности с физиологическими процессами. При этом, однако, мы не находим в них прямого ответа на вопрос, как физиологически возможна рефлексия, которая тоже является психическим процессом. В этой связи и складывается впечатление, что рефлексия дана человеку над- и внефизиологично. Этот вопрос ставится не впервые.

Одним из первых мысль о рефлекторной (и, соответственно, физиологической) основе рефлексии высказал Л. С. Выготский: рефлексия есть «всякое перенесение переживания с внешнего мира на самого себя» [6, с. 228]. При этом, как известно [7], переживание - реакция субъекта на внешнее или внутреннее раздражение - есть не что иное, как рефлекс. Но Л. С. Выготский, «намекнув» на связь рефлексии с рефлексом, далее в своих исследованиях не раскрывает эту связь.

Не раскрыта эта связь и в настоящее время, оставаясь на уровне вопроса, который в рамках исследования психологии рефлексивных механизмов деятельности задаёт А. В. Карпов: «Как в процессе эволюции становится возможной обращённость организма на себя, на особенности своего функционирования?» [8, с. 80]. С его 
точки зрения, «не исключено, что в конечном счёте физиологическим основанием этого является кольцеобразный (точнее, спиралевидный) принцип, заложенный в архитектонику любой функциональной системы организации в целом и психики в особенности» [8, с. 80-81]. При этом, как известно, основатели теории функциональных систем [9] никогда не отрицали рефлекторный принцип психической деятельности. Всё сказанное выше даёт основание для гипотезы, согласно которой и на рефлексию возможно перенести принцип рефлекса.

Как выше уже отмечалось, в психологии и физиологии практически нет работ, в которых непосредственно установлена связь между рефлексией и рефлексом. С нашей точки зрения, такая связь может быть установлена опосредованно - через «мышление». Ведь согласно Л. С. Выготскому, «мыслить - значит иметь способность одного условного рефлекса становиться раздражителем для нового условного рефлекса» [5, с. 50-51]. В свою очередь и рефлексия определяется через мышление, представляя собой «мыслительный (рациональный) процесс, направленный на анализ, понимание, осознание себя: собственных действий, поведения, речи, опыта, чувств, состояний, способностей, характера, отношений к себе и к др., своих задач, назначения и т.д.» [10, с. 469]. Возможно, именно установление связи между мышлением и рефлексом и позволит привести аргументы, подтверждающие нашу гипотезу о связи рефлексии с рефлексом.

В работах Л. С. Выготского сказано, что весь психологический механизм поведения человека, в том числе и мышления, «раскрывается ключом» условного рефлекса. Отметим, что речь в данном случае идёт об условном рефлексе как основании психологического механизма поведения, и Л. С. Выготский предупреждает о том, «что рефлекс есть фундамент, но по фундаменту ещё ничего нельзя сказать, что будет на нем построено» $[6$, с. 626]. В этой связи, разъясняя свою позицию, учёный отмечает: «Человек вовсе не кожаный мешок, наполненный рефлексами, и мозг не гостиница для случайно останавливающихся рядом условных рефлексов» [6, с. 624]. Согласно Л. С. Выготскому, ощущения, жесты, мимика и речь есть рефлексы, а мыслительный акт как высшее проявление психики представляет собой «передаточный механизм между системами рефлексов» [5, с. 51].

Л. С. Выготский, с одной стороны настаивает на том, что мыслительный акт не является условным рефлексом, с другой - что высшие процессы сознания «удивительно напоминают павловские условные рефлексы» [5, с. 94]. И в этой связи, чтобы понять, почему Л. С. Выготский, говоря о мыслительном акте, называет его не рефлексом, а «передаточным механизмом между системами рефлексов» и одновременно относит высшие процессы сознания к «павловским условным рефлексам», рассмотрим, что представляет собой «передаточный механизм между системами рефлексов» с точки зрения учёного.

Как устроен «передаточный механизм между системами рефлексов», Л. С. Выготский не описывает подробно, ограничиваясь утверждением, что «именно способность одного рефлекса (переживания предмета) быть раздражителем (предметом переживания) для нового рефлекса (нового переживания) - этот механизм сознательности и есть механизм передачи рефлексов из одной системы в другую» [5, с. 50]. Это утверждение, по сути, отражает позицию учёного в пользу рефлекторной природы мышления. Далее в работах психолога мы встречаем формулировку «закона связи рефлексов», который, по нашему мнению, может способствовать более полному разъяснению «механизма передачи рефлексов». В формулировке закона Л. С. Выготским «рефлексы связываются между собой по законам условных рефлексов, причем ответная часть одного рефлекса может стать при соответствующих условиях условным раздражителем (или тормозом) другого рефлекса, замыкаясь по сенсорному пути связанных с ним периферических раздражений в рефлекторную дугу с новым рефлексом» [6, с. 632]. На наш взгляд, в соответствии с этим законом передачу рефлексов можно понимать как связь тоже посредством рефлексов, но уже условных. И тогда мышление, мыслительный акт, будучи, по Л. С. Выготскому, «передаточным механизмом между системами рефлексов», а не рефлексом, в своей основе имеет рефлекс, но уже условный. Л. С. Выготский утверждает, что мыслительный акт - это не рефлекс, это «передаточный механизм между системами рефлексов», который, в свою очередь, осуществляется согласно «механизму» условных рефлексов. Но это ещё не означает, что мыслительный акт - это условный рефлекс, хотя, следуя логике Л. С. Выготского, от этой мысли трудно отказаться.

Одним из подтверждений нашего предположения о рефлекторной природе мышления в исследованиях Л. С. Выготского может служить его понимание единства аффективных и интеллектуальных процессов. Для отражения этого единства учёный вводит понятие динамической смысловой системы, представляющей собой систему аффективных и интеллектуальных процессов. Говоря о единстве мышления и аффекта, он подчеркивает, «что во всякой идее содержится 
в переработанном виде аффективное отношение человека к действительности, представленной в этой идее» [6, с. 57]. Это утверждение Л. С. Выготского, с нашей точки зрения, отражает процесс функционирования динамической смысловой системы, а именно: направление мышления определяется потребностью и побуждениями человека и обратно - динамика мысли определяет динамику поведения и конкретную деятельность.

Сказанное выше свидетельствует о том, что аффективные процессы, хотя и не есть само мышление, но представляют собой внутренние системные составляющие мышления, влияющие на ход и результат мыслительной деятельности. По этому поводу Л. С. Выготский говорит: «Кто оторвал мышление с самого начала от аффекта, тот навсегда закрыл себе дорогу к объяснению причин самого мышления, потому что детерминистический анализ мышления необходимо предполагает вскрытие движущих мотивов мысли, потребностей и интересов, побуждений и тенденций, которые направляют движение мысли в ту или другую сторону» [6, с. 57]. Однако следует понимать и помнить, что причины мышления не тождественны ему.

Следующим подтверждением нашего предположения является то, что в своих рефлексологических и психологических исследованиях Л. С. Выготский, напрямую следуя за В. М. Бехтеревым и А. М. Кроллем, называет «явления в области безобразного и бессловесного мышления» «павловскими условными рефлексами» [5, c. 48]. И в пользу связи мышления и рефлекса Л. С. Выготский принимает идею В. М. Бехтерева о том, что «мысль только заторможенный рефлекс, задержанный, оборванный на двух третях рефлекс, в частности, словесное мышление - наиболее частный случай задержанного речевого рефлекса» [5, с. 47]. Далее Л. С. Выготский отождествляет задержанные рефлексы и мысли, отмечая, что «задержанные рефлексы (= мысли)» $[5$, с. 48].

Третьим и наиболее убедительным, с нашей точки зрения, подтверждением рефлекторной сущности мышления в трудах Л. С. Выготского является выделение учёным в иерархии навыков интеллектуальных реакций. По его определению, интеллектуальные реакции представляют собой навыки, приобретенные в опыте и направленные на решение новых задач, возникающих перед организмом. При этом он называет «мышление в понятиях» высшей формой интеллектуальной деятельности, тем самым, по сути, отождествляя мыслительную деятельность с интеллектуальной, содержательно представленную интеллектуальными реакциями.
Существенным отличием интеллектуальных реакций, по мнению Л. С. Выготского [11], является то, что они возникают в результате какого-то «короткого замыкания» и являются сложными реакциями взрывного типа. При этом интеллектуальная реакция как условный рефлекс формируется в процессе «перенесения» внутрь личности коллективных социальных отношений и форм поведения, в результате чего образуется индивидуальная форма поведения. Процесс «переноса» внутрь личности социальных отношений и форм поведения Л. С. Выготский связывает с интериоризацией.

Заканчивая анализ работ Л. С. Выготского, направленных на выявление связи мышления с рефлексом, подведем итог исследования, выделив основные идеи, касающиеся рефлекторной природы мышления:

1) мыслительная деятельность, или мыслительный акт, согласно Л. С. Выготскому, представляет собой «передаточный механизм между системами рефлексов», в основе которого лежит способность одного условного рефлекса становиться раздражителем для нового условного рефлекса, что, по сути, говорит о рефлекторном принципе мышления;

2) введенное Л. С. Выготским понятие динамической смысловой системы, представляющей собой единство аффективных и интеллектуальных процессов, ввиду рефлекторной сущности аффективных процессов и их влияния на ход и результат интеллектуальных процессов как внутренних системных составляющих, даёт повод предположить рефлекторное основание интеллектуальных процессов;

3) Л. С. Выготский отождествляет мысль и задержанный рефлекс, который он иначе называет заторможенным, оборванным на двух третях рефлексом и связывает с сосредоточением, вызванным «задержкой нервного тока»;

4) интеллектуальные реакции, выделенные Л. С. Выготским в качестве высших реакций в иерархии навыков, формирующиеся посредством интериоризации психических функций в результате индивидуального приобретенного опыта, самим учёным относятся к классу условных рефлексов.

Таким образом, анализ результатов исследований Л. С. Выготского позволил выявить аргументы, свидетельствующие в пользу нашего предположения о рефлекторном принципе мышления.

\section{Список литературы}

1. Жилин В. И. Синергетический сциентизм : критический анализ философско-методологических оснований. М., 2011. 192 с. 
2. Шатова Н. Д. Связь терминов «рефлекс» и «рефлексия» для психолого-педагогических исследований : лексический и логический аспекты // Изв. Сарат. ун-та. Нов. сер. Сер. Философия. Психология. Педагогика. 2015. Т. 15, вып. 1. С. 111-118.

3. Шатова Н. Д. Генезис понятия «рефлекс» : от реактивности Р. Декарта к условному рефлексу И. П. Павлова // Вестн. алтайской науки. 2014. № 4. С. 364-370.

4. Шатова Н. Д. Генезис понятия «рефлекс» : от условного рефлекса И. П. Павлова к физиологии активности Н. А. Бернштейна // Вестн. алтайской науки. 2014. № 4. С. 370-374.

5. Выготский Л. С. Собр. соч. : в 6 т. / под ред. А. Р. Лурия, М. Г. Ярошевского. М., 1982. Т. 1. 488 с.

6. Выготский Л. Мышление и речь : сб. М., 2008. $668 \mathrm{c}$.

7. Ефремова Т. Ф. Новый словарь русского языка. Толково-образовательный. М., 2000. 1088 с.

8. Карпов А. В. Психология рефлексивных механизмов деятельности. М., 2004. 424 с.

9. Функциональные системы организма : руководство / под ред. К. В. Судакова. М., 1987. 432 с.

10. Большой психологический словарь / сост. и общ. ред. Б. Мещерякова, В. Зинченко. СПб., 2004. 672 с.

11. Выготский Л. С. Собр. соч. : в 6 т. Т. 3. Проблемы развития психики / под ред. А. М. Матюшкина. M., $1983.368 \mathrm{c}$.

\section{Prolegomena to Search of Reflex Bases of the Reflection: L. S. Vygotsky}

\section{N. D. Shatova}

Omsk State Pedagogical University

14, Tukhachevskiy quay, Omsk, 644099, Russia

E-mail: Shatova.nat@yandex.ru

The attempts to introduce a reflective approach in Patriotic education were frequently unsuccessful that, in the author's opinion, due to the lack of attention to materialist positions of psychologists, according to which, effectively forming the reflective capacity of students may, based on well understood laws governing the formation of conditional reflexes of man. In this context, the author identifies the connection between reflection and reflex in order to use its relationship as the fundamental basis of the concept of reflective learning. The relationship between reflection and reflex, the author establishes indirectly through "thinking» and finding arguments in favor of the reflexive nature of thinking refers to the works of L. S. Vygotsky.

Key words: L. S. Vygotsky, thinking, reflex, reflection.

\section{References}

1. Zhilin V. I. Sinergeticheskiy stsientizm: kriticheskiy analiz filosofsko-metodologicheskikh osnovaniy (Synergetic scientism: Critical analysis of the philosophical and methodological bases). Moscow, 2011. 192 p.

2. Shatova N. D. Svyaz terminov «reflex» i «refleksiya» dlya psikhologo-pedagogicheskikh issledovaniy: leksicheskiy i logicheskiy aspekty (The relationship of the terms «reflex» and «reflection» for psychological and educational research: lexical and logical aspects). Izv. Saratov Univ. (N.S.), Ser. Philosophy. Psikhology. Pedagogy, 2015, vol. 15, iss. 1, pp. 111-118.

3. Shatova N. D. Genezis ponyatiya «reflex»: ot reaktivnosti R.Dekarta k uslovnomu refleksu I. P. Pavlova (Genesis of the concept «reflex»: from R. Descartes reactivity to a conditioned reflex of I. P. Pavlov). Vestnik altayskoy nauki (Vestnik altaiskoy nauki), 2014, no. 4, pp. 364-370.

4. Shatova N. D. Genezis ponyatiya «reflex»: ot uslovnogo refleksa I. P. Pavlova k fiziologii aktivnosti N. A. Bernshteina (Genesis of the concept «reflex»: from a conditioned reflex of I. P. Pavlov to physiology of activity of N. A. Bernstein). Vestnik altayskoy nauki (Vestnik altaiskoy nauki), 2014, no. 4, pp. 370-374.

5. Vygotskiy L. S. Sobr. soch.: $v 6 t$. (Collected works: in 6 vol.). Moscow, 1982. Vol. 1. 488 p.

6. Vygotskiy L. S. Myshlenie i rech (Thinking and speech). Moscow, 2008. 668 p.

7. Efremova T. F. Novyy slovar russkogo yazyka. Tolkovoobrazovatelnyy (New dictionary of Russian. Sensible and educational). Moscow, 2000. 1088 p.

8. Karpov A. V. Psikhologiya refleksivnykh mekhanizmov deyatelnosti (Psychology of reflexive mechanisms of activity). Moscow, 2004. 424 p.

9. Funktsionalnye sistemy organizma. Pod red. K. V. Sudakova (Functional systems of an organism. Ed. by K. V. Sudakov). Moscow, 1987. 432 p.

10. Bolshoy psikhologicheskiy slovar. Sost. i obshch. red. B. Meshcheryakov, V. Zinchenko (Big psychological dictionary. Originator and general editor B. Meshcheryakov, V. Zinchenko). St.-Petersburg. 2004, 672 p.

11. Vygotskiy L.S. Sobr. soch.: v $6 t$. (Collected works: in 6 vol.). Moscow, 1983. Vol. 3. 368 p. 